\title{
Certainty of fertility preferences among Dutch women
}

\author{
Gert Stulp ${ }^{1}$ \\ ${ }^{a}$ Department of Sociology 85 Inter-University Center for Social Science Theory and \\ Methodology, Grote Rozenstraat 31, 9712 TS, Groningen, the Netherlands
}

\begin{abstract}
BACKGROUND

Studies on fertility preferences have highlighted a gap between preferred and realised fertility. Here we examine two potential determinants of this fertility gap: how certain people are in their preferred fertility, and to what extent there is partner agreement on this preferred number.

\section{METHODS}

A sample of 758 women between the ages of 18 and 40 were recruited through the Longitudinal Internet Studies for the Social Sciences-panel, a representative sample of Dutch individuals.

\section{RESULTS}

Only $21 \%$ of women without children and $48 \%$ of mothers were certain about their fertility preferences. With increasing preferred number of children, certainty in this preference decreased. More than half of respondents agreed with their partner on the preferred number, and agreement decreased for increasing preferred number of children. There was agreement in $90 \%$ of the couples on not having children, and $80 \%$ of mothers agreed with their partner on having

Email address: g.stulp@rug.nl (Gert Stulp) 
only one child. This decreased to $40 \%$ agreement in women that preferred more than three children.

\section{CONCLUSIONS}

Dutch women were uncertain about their fertility preferences, particularly in those without children. There was more uncertainty and partner disagreement surrounding preferences for larger than for smaller number of children. Both uncertainty and disagreement likely lower fertility.

\section{CONTRIBUTION}

This study gives a detailed look on how the certainty of fertility preferences and partner agreement vary by the preferred number of children. Findings help explain the persistent gap between preferred fertility and realised fertility.

\section{Keywords}

fertility preferences; strength of preference; partner agreement; fertility gap; LISS panel 


\section{Introduction}

Fertility preferences can shed light on future fertility levels, yet it is the difference between preferred and realised fertility that is currently of more interest to demographers (Beaujouan and Berghammer 2019; Hin et al. 2011; Liefbroer 2009). In many contemporary Western populations, there is a gap between how many children people prefer, by and large two, and how many children people have, by and large below two (Beaujouan and Berghammer 2019; Bongaarts 2001). The rising ages at childbearing, adverse economic circumstances, medical infertility, competing preferences, and work-life balance all contribute to explaining the gap (Beaujouan and Berghammer 2019; Bongaarts 2001). The fertility gap is picked up by policy makers (Philipov 2009), who can alleviate institutional barriers to childbearing in order for people to better realise their fertility intentions. Here we focus on two factors that may similarly explain the fertility gap but that have nothing to do with aforementioned factors: (1) the certainty of fertility preferences, and (2) partner agreement on fertility preferences.

The fertility gap can also arise due to the way fertility preferences are typically measured, which has received its fair share of critique (Bhrolcháin and Beaujouan 2019; Thomson 2015). For instance, substantial ambiguity and inconsistencies exist in the different forms of measuring fertility preferences (Bhrolcháin and Beaujouan 2019; Philipov and Bernardi 2011). Moreover, fertility preferences should not be seen as static, but as as a moving target (Lee 1980) that change over the lifecourse (Liefbroer 2009; Verweij et al. 2019) de- 
pending on life circumstances including experiences with earlier births (Margolis and Myrskylä 2015). Bhrolcháin and Beaujouan (2019) even argue that fertility preferences are constructed at the time of survey on the basis of available information at that time (rather than being retrieved from memory). There is further plenty of evidence that fertility preferences can be uncertain and that they vary in strength (Hin et al. 2011; Terhune and Kaufman 1973; Thomson 2015). Some people may feel strongly about a particular family size, whereas other are not attached to a particular number, but have a range of acceptable family sizes in mind (Coombs 1974). In one of the few studies on the strength of preferences, Hin et al. (2011) found that a substantial number of people had no strong preference for their first preferred fertility over their second preferred fertility. These findings are important, because they help explain the fertility gap: for example, if people are less certain about their preferences for larger family sizes than for smaller family sizes, or if people are more accepting of family sizes below than above ideally preferred (Hin et al. 2011), then it is not surprising that realised fertility is often lower than preferred fertility.

Certainty about one's own fertility preferences can also stem from (dis)agreement with the partner on ideal preferences. In the absence of strong assortative mating for fertility preferences, partners are likely to hold different preferences (Voas 2003). Both partners' fertility desires matter in fertility outcomes (Bauer and Kneip 2013; Thomson 2015), and in resolving differences couples are less likely to become parent (Bauer and Kneip 2014) or pursue additional births (Thomson 1997; Thomson and Hoem 1998) when one partner prefers not to have (more) 
children. Thus, ideal fertility tends to be downgraded when partners disagree. Partner disagreement is thus another reason why realised fertility is often lower than personal preferences (Thomson 2015; Voas 2003).

The current study describes the certainty of fertility preferences in a sample of Dutch women in two ways: (1) by asking about the strength of their fertility preferences, and (2) by asking about the agreement with the partner on these preferences. This study advances existing studies by the detailed way of asking about the strength of preference and agreement with partner, and by investigating how certainty and agreement vary for each preferred number of children. Findings help explain part of the gap between preferred and realised fertility observed in many populations.

\section{Methods}

\subsection{Participants}

In this paper we make use of data of the LISS (Longitudinal Internet Studies for the Social sciences) panel administered by CentERdata (Tilburg University, The Netherlands). The LISS panel is a representative sample of Dutch individuals who participate in monthly Internet surveys. The panel is based on a true probability sample of households drawn from the population register by Statistics Netherlands (CBS). Much effort was put into ensuing a representative sample and high response rates. The resulting representativeness of the LISS-panel was similar to those from traditional surveys based on probability sampling (Knoef and de Vos 2009; Scherpenzeel and Bethlehem 2011). Initial 
selection biases were substantially corrected by refreshment samples, and further refreshment samples were planned for attrition biases (Scherpenzeel 2011).

The LISS-panel allows researchers to do their own survey within the panel. We added a study named the Social networks and fertility survey that focused on social influences on fertility desires and outcomes. For this survey all women in the LISS panel between the ages of 18 and $40(\mathrm{~N}=1332)$ were invited to participate between February 20 and March 27, 2018. In total, 758 women completed the survey with a mean age of $29.2(\mathrm{SD}=6.5)$. Ethical approval for this particular study was obtained through the ethical committee of sociology at the University of Groningen (ECS-170920). See Stulp (2020) and https://hdl.handle.net/10411/N2TIVF for further details on the study including the full questionnaire. Data will become available on https://www.lissdata.nl.

\subsection{Procedure}

The first part of the survey concerned questions about fertility and partnerships. The second part of the questionnaire involved detailed questions on the social networks of these women (Buijs and Stulp 2019; Stulp 2020), which will

not feature in the below analyses. The focus of this study is on the following items:

Preferred number of children: "How many children would you like to have? This is including the X children you already have."; options: 0 - 10, More than 10, I don't know.

Strength of preference: "You indicated in the previous question that you would like to have X children / X more children than you currently have. We 
would like to know how strong this preference is."; options: (1) I don't care much whether I will have (more) children, (2) I don't care much about the number of children; one child more or fewer is fine, (3) I really would like to become mother (again), but the number of children is not important, (4) Fewer children would be fine, but I'd rather not have more, (5) More children would be fine, but I'd rather not have fewer, (6) I'd rather not have more or fewer than ... children, (7) I don't really know. This question was not asked to people who responded with "I don't know" on preferred number of children.

Agreement with partner about preferred number of children: "Which statement best reflects the situation between you and your partner?"; options: (1) We both would not like to have (more) children, (2) We both would like to have (more) children, but we haven't discussed the preferred number, (3) We both like to have the same number of children, (4) I don't want more children, but my partner does, (5) I would like more children, but my partner doesn't, (6) My partner wants fewer children than I do, (7) My partner wants more children than I do, (8) I don't know. This question was only asked to women who indicated in a previous question that they had talked to their partner about having children. We collapsed categories (1) and (3), categories (4) and (7), and categories (5) and (6), and we added a category "Did not discuss with partner" based on the previous question. The resulting item has 6 categories: (1) Both want same number of children, (2) Both want children, but not discussed number, (3) Partner wants more children than I do, (4) Partner wants fewer children than I do, (5) I don't know, (6) Did not discuss with partner. 


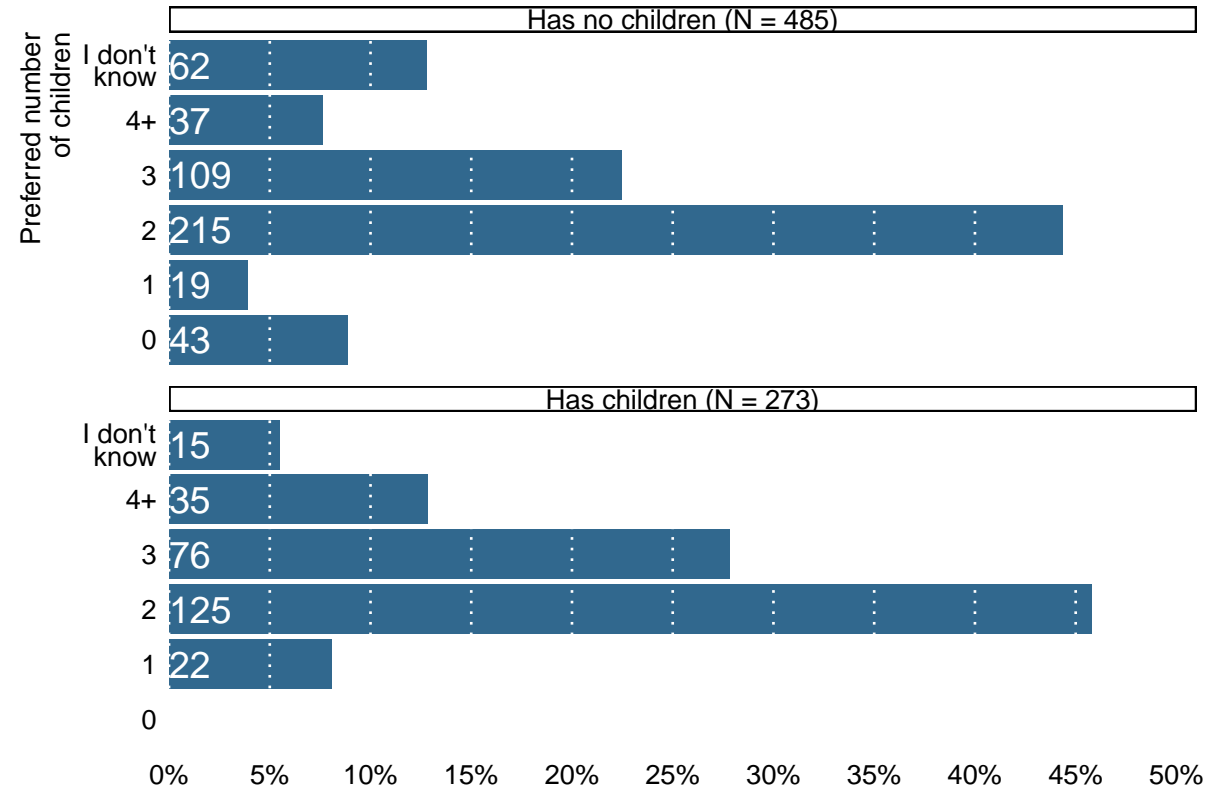

Figure 1: Preferred number of children for women with and without children. NOTE: N per group in white.

We show all findings separately for women with $(\mathrm{N}=273)$ and without $(\mathrm{N}$ $=485)$ children.

\section{Results}

\subsection{Preferred number of children}

A clear two child preference was visible as $45 \%$ chose two as the preferred number of children (Figure 1). Three children was the second most preferred option with $24 \%$. Only $6 \%$ preferred no children, and $5 \%$ one child. About $10 \%$ did not know their preferred family size. The distribution of preferences was similar for women with and without children. The biggest difference was that $9 \%$ of respondents without children preferred to have no children, whereas none of the mothers did. Mothers also responded less often with "I don’t know" 


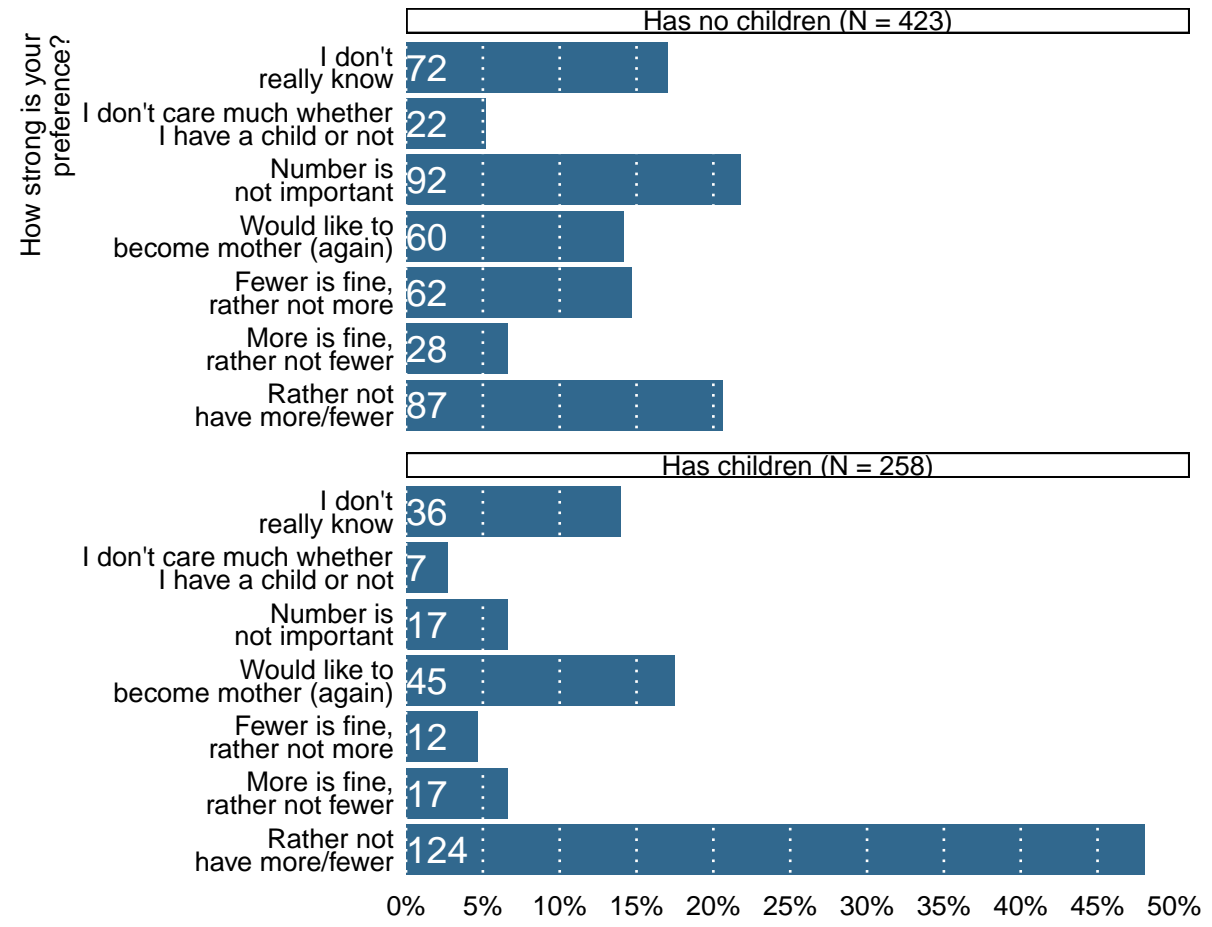

Figure 2: Strength of preference for preferred number of children. NOTE: N per group in white.

and more often preferred larger family sizes (3 and higher) compared to those without children.

\subsection{Strength of preference}

We subsequently asked people about the strength of their preference regarding the preferred number of children (Figure 2). Women without children were not very certain about their preferences: only $21 \%$ said that they would rather not have more or fewer than their preferred number. About as many women said that the number of children is not important $(22 \%)$. Furthermore, there were about twice as many respondents that thought that "fewer children is fine, but not more" than those that thought that "more children is fine, but not 


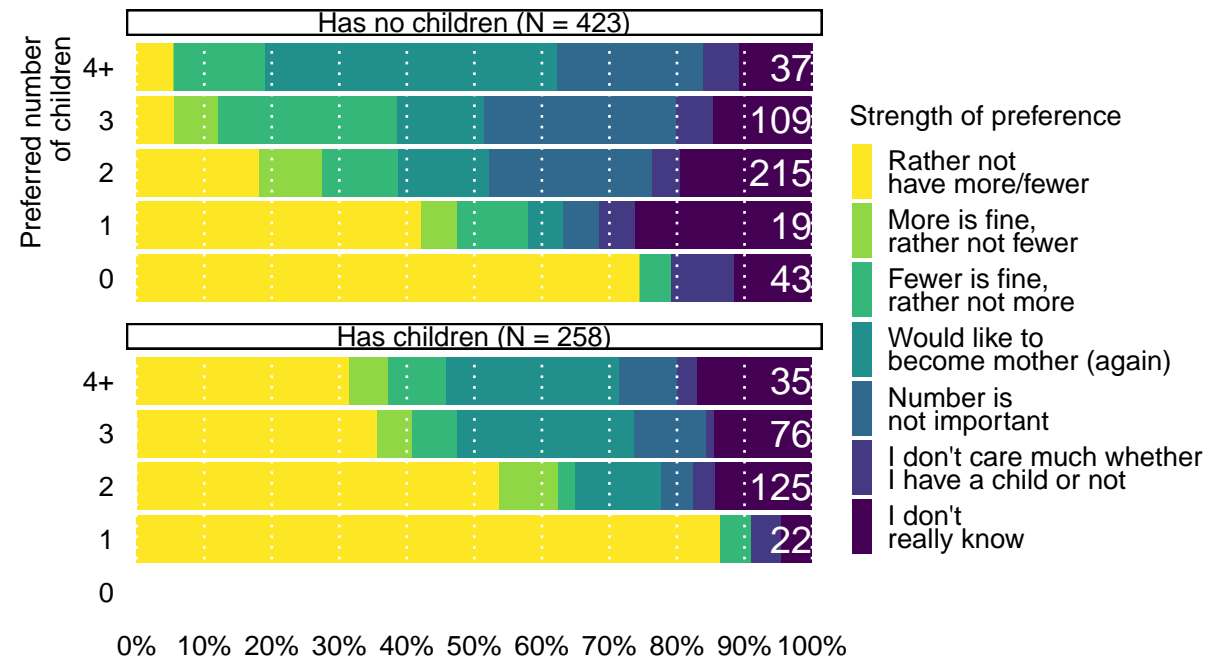

Figure 3: Strength of preference depends on the preferred number of children. NOTE: N per group in white.

fewer" (15\% and 7\%, respectively). Some respondents said they did not really care much about having children $(5 \%)$ whereas a substantial fraction said they didn't really know $(17 \%)$.

Mothers were much more certain about their preferences: 48\% said they would rather not have more or fewer children than their preferred number. A further $17 \%$ said that they would like to become mother again. Still, $14 \%$ were unsure about their preferences. Mothers were also less likely to say that the number is not important (7\%) or that fewer children is fine (5\%).

When examining the strength of preference for each preferred number of children (Figure 3), it is clear that the higher the number of preferred children, the lower the certainty of this preference (as indicated by the "rather not more/fewer" response). This is true for women with and without children. For women without children, $74 \%$ were certain about their preference to have no 


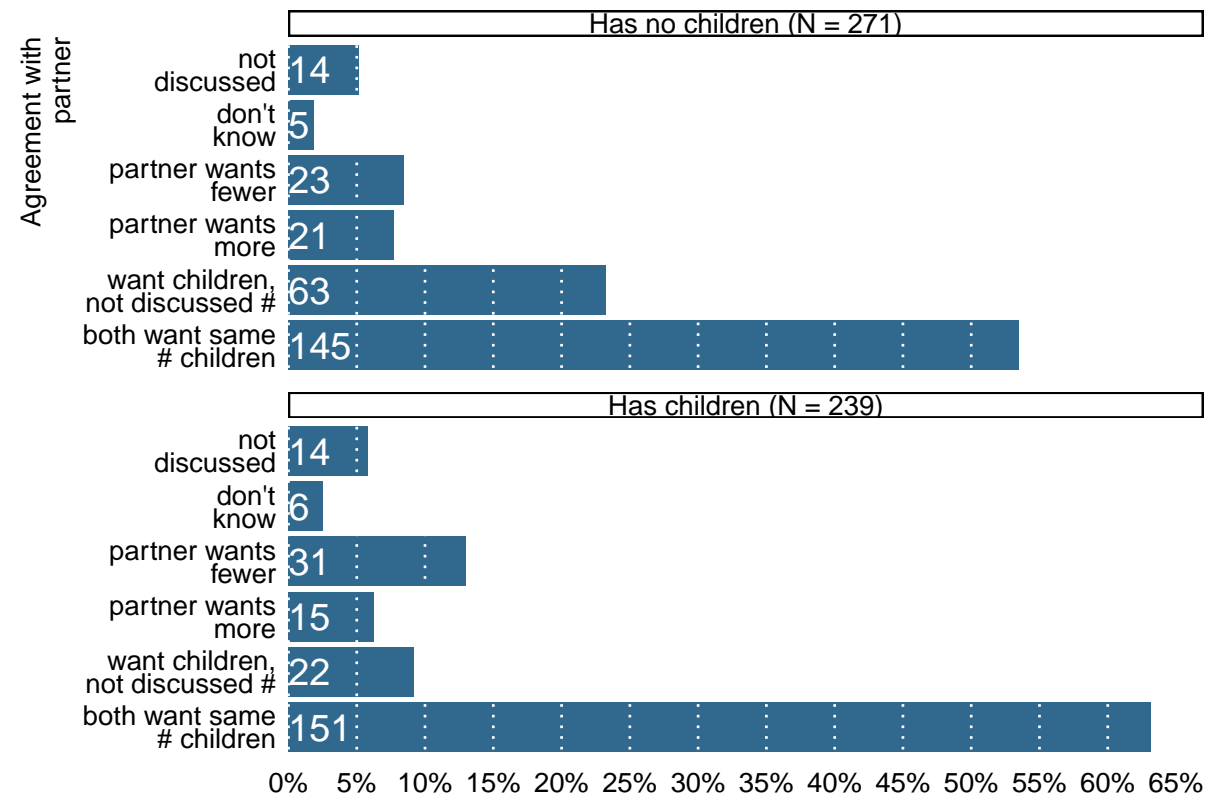

Figure 4: Agreement with partner over preferred number of children. NOTE: N per group in white.

children. This decreased to $42 \%$ for those who preferred to have 1 child, and only $18 \%$ for two children. In contrast, women who responded with "number is not important" increased with increasing preferred number of children. For each preferred number of children, it was the case that more respondents indicated that "fewer is fine, rather not more" compared to "more is fine, rather not fewer". Mothers were most certain about their preference for one child (54\%).

\subsection{Agreement with partner on preferred number of children}

A different way of investigating the certainty of preferences is to examine the agreement on the preferred number of children with the partner (Figure 4). More than half of respondents agreed with their partner on the preferred number ( $54 \%$ in women without children and $63 \%$ in mothers). The partner 


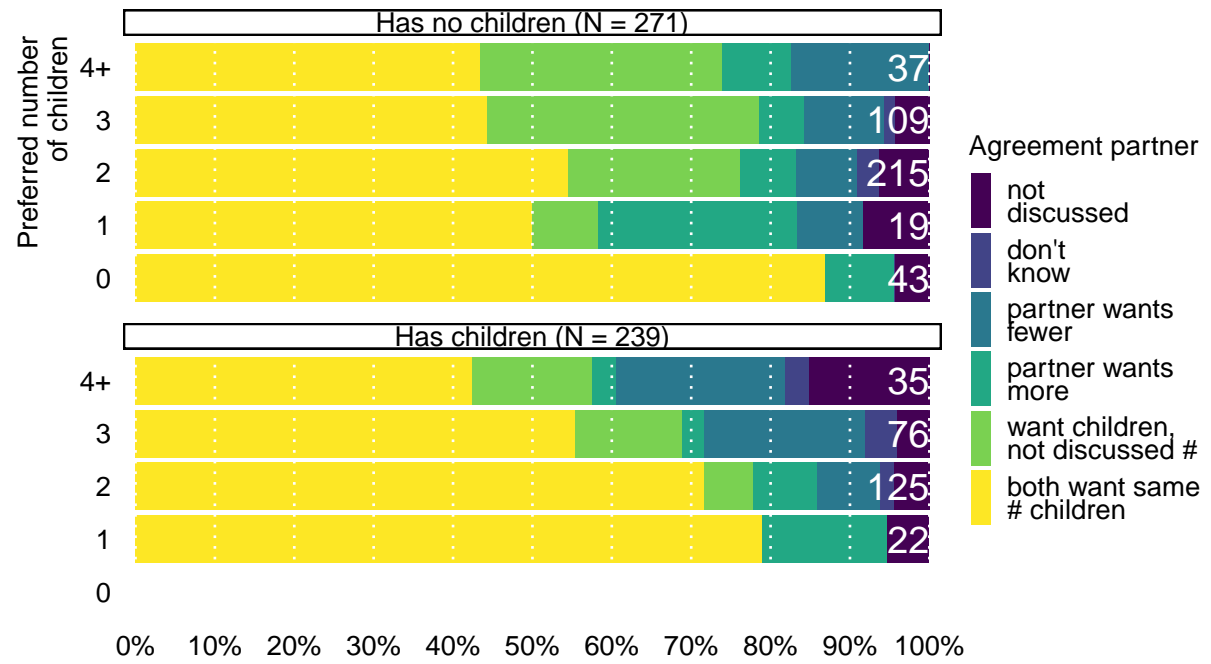

Figure 5: Agreement with partner on preferred number of children. NOTE: N per group in white.

wanted fewer children in $11 \%$ of the couples, and more in $7 \%$. About $5 \%$ had not discussed family size with their partner. Women without children had more often discussed having children, but not the preferred number compared to mothers $(23 \%$ versus $9 \%)$.

With increasing number of preferred children, agreement with the partner decreased (Figure 5). This ranges from $79 \%$ for mothers who prefer one child to $42 \%$ for mothers who prefer 4 or more children. In women without children, this pattern is less strong, although there is much more agreement on having no children (87\%) compared to having children (between $43 \%$ and $55 \%$ ).

\section{Discussion}

Dutch women did not express much certainty about their fertility preferences. It is insightful to examine the responses by the majority of women who 
preferred two children (45\%; in correspondence with the widely observed twochild norm). Only $18 \%$ of women without children preferred exactly two children, not more or fewer. There was much uncertainty given the $24 \%$ of women that indicated that the number was not important, $20 \%$ that did not know, $13 \%$ that indicated that they would like to become mother, but that one fewer or more would not matter, and $4 \%$ that said they did not care much. Thus, the majority of respondents was not certain about their preference for two children. Uncertainty was even more pronounced for women preferring 3 or more children, and women preferring no children or only one child expressed most certainty. Women without children were also more accepting of fewer than of more than their preferred number (in line with Hin et al. (2011)).

When examining partner agreement on fertility preferences, we again find that lower fertility preferences are associated with more certainty. There was agreement in $90 \%$ of the couples on not having children, and $80 \%$ of mothers agreed with their partner on having only one child. This decreased to $40 \%$ agreement in women that preferred more than three children. It must be noted that the stated preferences may already be 'contaminated' (Voas 2003) by partner's preferences, and that disagreement probably stronger at the start of a relationship.

These findings are important because they provide good explanations for the fertility gap. Because people are more certain about their preferences for lower numbers of children, and are more open to family sizes below than above their preferred choice, it is not surprising that realised fertility is often lower 
than preferred fertility. Similarly, partner disagreement is often resolved by not having (more) children (Bauer and Kneip 2014; Thomson 1997; Thomson and Hoem 1998), lowering realised fertility. These findings may also imply that the discrepancy between ideally preferred number and realised number is not considered a real loss (Hin et al. 2011).

\section{Funding}

The LISS panel data were collected by CentERdata (Tilburg University, The Netherlands) through its MESS project funded by the Netherlands Organization for Scientific Research. This work was further supported by the Netherlands Organisation for Scientific Research (VENI Grant 451-15-034).

\section{References}

Bauer, G. and Kneip, T. (2013). Fertility From a Couple Perspective: A Test of Competing Decision Rules on Proceptive Behaviour. European Sociological Review 29(3):535-548. doi:10.1093/esr/jcr095.

Bauer, G. and Kneip, T. (2014). Dyadic fertility decisions in a life course perspective. Advances in Life Course Research 21:87-100. doi:10.1016/j.alcr.2013.11.003.

Beaujouan, E. and Berghammer, C. (2019). The gap between lifetime fertility intentions and completed fertility in Europe and the United States: A cohort approach. Population Research and Policy Review 38(4):507-535. doi:10.1007/s11113019-09516-3.

Bhrolcháin, M.N. and Beaujouan, É. (2019). Do people have reproductive 
goals? Constructive preferences and the discovery of desired family size. In: Schoen, R. (ed.). Analytical Family Demography. Cham: Springer International Publishing: 27-56. doi:10.1007/978-3-319-93227-9_3.

Bongaarts, J. (2001). Fertility and Reproductive Preferences in Post-Transitional Societies. Population and Development Review 27:260-281.

Buijs, V.L. and Stulp, G. (2019). Friends, Family, and Family Friends: Predicting Friendships of Dutch Women. Open Science Framework.: pages. doi:10.31219/osf.io/y5dh7.

Coombs, L.C. (1974). The measurement of family size preferences and subsequent fertility. Demography 11(4):587-611. doi:10.2307/2060472.

Hin, S., Gauthier, A., Goldstein, J., and Bühler, C. (2011). Fertility preferences: What measuring second choices teaches us. Vienna Yearbook of Population Research 9:131-156.

Knoef, M. and de Vos, K. (2009). The Representativeness of LISS, an Online Probability Panel. Tilburg: CentERdata.: pages.

Lee, R.D. (1980). Aiming at a moving target: Period fertility and changing reproductive goals. Population Studies 34(2):205-226. doi:10.1080/00324728.1980.10410385.

Liefbroer, A.C. (2009). Changes in Family Size Intentions Across Young Adulthood: A Life-Course Perspective. European Journal of Population / Revue européenne de Démographie 25(4):363-386. doi:10.1007/s10680-008-9173-7.

Margolis, R. and Myrskylä, M. (2015). Parental well-being surrounding first birth as a determinant of further parity progression. Demography 52(4):1147- 
66. doi:10.1007/s13524-015-0413-2.

Philipov, D. (2009). Fertility Intentions and Outcomes: The Role of Policies to Close the Gap. European Journal of Population / Revue européenne de Démographie 25(4):355. doi:10.1007/s10680-009-9202-1.

Philipov, D. and Bernardi, L. (2011). Concepts and Operationalisation of Reproductive Decisions Implementation in Austria, Germany and Switzerland. Comparative Population Studies 36(2-3).

Scherpenzeel, A.C. (2011). Data collection in a probability-based internet panel: How the liss panel was built and how it can be used. BMS: Bulletin of Sociological Methodology / Bulletin de Méthodologie Sociologique(109):56-61.

Scherpenzeel, A.C. and Bethlehem, J.G. (2011). How Representative Are Online Panels? Problems of Coverage and Selection and Possible Solutions. In: Social and Behavioral Research and the Internet. Advances in Applied Methods and Research Strategies. Marcel Das, Peter Ester, Lars Kaczmirek. Routledge. doi:10.4324/9780203844922-5.

Stulp, G. (2020). Collecting Large Personal Networks in a Representative Sample of Dutch Women. Open Science Framework.: pages. doi:10.31219/osf.io/efkuw.

Terhune, K.W. and Kaufman, S. (1973). The family size utility function. Demography 10(4):599-618. doi:10.2307/2060886.

Thomson, E. (1997). Couple childbearing desires, intentions, and births. Demography 34(3):343-354. doi:10.2307/3038288.

Thomson, E. (2015). Family Size Preferences. In: Elsevier: 805-808.

Thomson, E. and Hoem, J.M. (1998). Couple childbearing plans and births 
in Sweden. Demography 35(3):315-322. doi:10.2307/3004039.

Verweij, R., Stulp, G., Snieder, H., and Mills, M.C. (2019). Can Fertility Desires and Expectations Explain the Association of Education and Occupation with Childlessness? Open Science Framework.: pages. doi:10.31219/osf.io/p37yj. Voas, D. (2003). Conflicting Preferences: A Reason Fertility Tends to Be Too High or Too Low. Population and Development Review 29(4):627-646. doi:10.1111/j.1728-4457.2003.00627.x. 